International Journal of Medical Sciences

ISSN 1449-1907 www.medsci.org 2006 3(2):57-62

Review

(C)2006 Ivyspring International Publisher. All rights reserved

\title{
Hepatitis B Virus (HBV) and Hepatitis C Virus (HCV) Dual Infection
}

\author{
Zhihua Liu, and Jinlin Hou
}

Department of Infectious Diseases and Hepatology Unit, Nanfang Hospital, Southern Medical University, Guangzhou, China

Corresponding address: Jinlin Hou, M.D, Hepatology Unit and Dept. of Infectious Diseases, Nanfang Hospital, Guangzhou 510515, China. email: jlhou@fimmu.com Tel: 86-20-61641941 Fax: 86-20-87714940

Received: 2005.12.30; Accepted: 2006.03.15; Published: 2006.04.01

Hepatitis $B$ virus (HBV) and hepatitis $C$ virus $(\mathrm{HCV})$ infections account for a substantial proportion of liver diseases worldwide. Because the two hepatotropic viruses share same modes of transmission, coinfection with the two viruses is not uncommon, especially in areas with a high prevalence of HBV infection and among people at high risk for parenteral infection. Patients with dual HBV and $\mathrm{HCV}$ infection have more severe liver disease, and are at an increased risk for progression to hepatocellular carcinoma (HCC). Treatment of viral hepatitis due to dual HBV/HCV infection represents a challenge.

Key words: Hepatitis B virus, hepatitis C virus, coinfection, epidemiology, hepatocellular carcinoma (HCC)

\section{Introduction}

Approximately 350 million people are infected with HBV worldwide, and the World Health Organization (WHO) estimates that approximately 170 million people are infected with HCV. HBV and HCV infection account for a substantial proportion of liver diseases worldwide. Because the two hepatotropic viruses share same modes of transmission, coinfection with the two viruses is not uncommon, especially in areas with a high prevalence of HBV infection and among people at high risk for parenteral infection. The exact number of patients infected with both HCV and HBV is unknown.

\section{Epidemiology}

Dual infection with HBV and HCV is not uncommon in geographic areas where a high endemic level of both infections is reported, such as Southeast-Asia and Mediterranean. In general, the prevalence is around 10$20 \%$ in patients with chronic HBV infection (see table1) [1$10]$, and $2-10 \%$ of anti-HCV-positive patients to have markers of $\mathrm{HBV}$ infection. In addition to chronic liver diseases, coinfection of HBV and $\mathrm{HCV}$ is frequently found in injection drug users (IDU, 42.5\%) [11], patients on hemodialysis $(3.7 \%)$ [12], patients undergoing organ transplantation (8\%) [13], HIV-positive individuals (66\%) [14], and beta-thalassemia patients (10\%) [15], which means that those are the high risk population for infection of HBV and HCV concurrently. A multicenter study in Italy [16] showed that the subjects with dual HBV and $\mathrm{HCV}$ infection were more likely to be older than 42 years, resident in the south of the country, to have a history of blood transfusion, i.v. drug use, unsafe sex, use of glass syringes or light alcohol use and to have a lower education level. Independent predictors of dual infection were age $>42$ years, history of i.v. drug use (IDU), blood transfusion and residence in the south of the country. Liaw [17] identified risk factors for HCV superinfection in 23 hepatitis B patients including blood transfusion, IDU, instrumentation and household or community contact. Among HIV-infected people, HBV and HCV coinfection was as high as 66\% (80 of 133) and coinfection was seen more frequently in drug users (84\%) in comparison with the patients infected by homosexual $(66 \%)$ or heterosexual
(20\%) route [14]. Totally, the risk factors of dual infection are similar to those of single infection of the two viruses, including IDU, blood transfusion, unsafe sexual contact, and other parenteral transmission modes and IDU and blood transfusion are the two major modes which account for nearly $90 \%$ of dual infection.

Table 1. Prevalence of serum anti-HCV-positive in HBsAgpositive patients with chronic liver diseases

\begin{tabular}{|c|c|c|c|c|c|c|}
\hline Geographic & Year & Author & No. & \multicolumn{2}{|c|}{ Anti-HCV } & \multirow{2}{*}{ Reference } \\
\cline { 4 - 6 } & & & & No. & $\%$ & \\
\hline China & 1999 & Chen & 712 & 103 & 14.47 & {$[1]$} \\
\hline & 1994 & Li & 193 & 22 & 11.39 & {$[2]$} \\
\hline Japan & 1994 & Sato & 82 & 18 & 23 & {$[3]$} \\
\hline & 1994 & Ohkawa & 156 & 20 & 12.8 & {$[4]$} \\
\hline Taiwan & 1994 & Liaw & 1498 & 173 & 12 & {$[5]$} \\
\hline & 1991 & Chan & 323 & 11 & 3.4 & {$[6]$} \\
\hline Italy & 2003 & Gaeta & 837 & 59 & 7 & {$[7]$} \\
\hline & 1999 & Di Marco & 302 & 43 & 14.2 & {$[8]$} \\
\hline & 1991 & Fattovich & 184 & 27 & 15 & {$[9]$} \\
\hline Spain & 1994 & Crespo & 132 & 17 & 13 & {$[10]$} \\
\hline
\end{tabular}

3. Clinical feature of coinfection with $\mathrm{HBV}$ and $\mathrm{HCV}$

Simultaneous HBV and HCV Infection in Acute Hepatitis

Because the patients with $\mathrm{HBV}$ and HCV acute coinfection are limited and only a few reports are available, little is known about this aspect. Five patients with acute HBV and HCV coinfection observed by Mimms have a lower level of HBsAg and ALT as compared with patients with acute HBV infection alone, and four of them developed chronic HCV infection [18]. The result indicated that onset of hepatitis $B$ may reduce the severity of $\mathrm{HCV}$ infection but not frequency of chronicity. Similar to this study, Sagnelli [19] reported 3 patients with acute $\mathrm{HBV}$ and $\mathrm{HCV}$ coinfection recovered from $\mathrm{HBV}$ infection and progressed to HCV-related chronic hepatitis and none of the 3 patients had a severe form of acute hepatitis. However, Chu and Liaw [20] have described a serologically and virologically proven case of acute $\mathrm{HCV}$ and HBV coinfection presenting as biphasic ALT elevation with fulminant hepatitis. Furthermore, Alberti [21] studied 30 patients with symptomatic acute hepatitis in whom markers of active $\mathrm{HBV}$ and $\mathrm{HCV}$ infection were found to coexist. All patients were 
observed during the acute hepatitis and were followed for a long time after acute hepatitis, and their clinical features and outcome were compared with those of patients suffering from acute hepatitis due to single HBV and HCV infection. The acute phase peak in transaminase activity was particularly high in patients with mixed HBV and $\mathrm{HCV}$ infection, but chronicity rates of hepatitis $\mathrm{B}$ and of hepatitis $C$ were not modified, and were similar to those of patients with single infection. When individual patients were monitored during the acute phase, at least two distinct peaks of alanine aminotransferase (ALT) were observed in patients with dual infection, independently of whether hepatitis then resolved or progressed to chronicity.

From above, coinfection of HBV and HCV in acute hepatitis will progress to HCV-related chronic hepatitis and the chronicity rates are not modified, but the severity of hepatitis in patients with dual infection is not accordance in these studies.

\section{HBV and HCV Coinfection in Patients with Chronic Liver Diseases}

Although dual infection with HBV and HCV leads to mutual suppression of both viruses, several studies have suggested that multiple HBV and HCV infection may be associated with more severe clinical presentation $[9,10]$. A Saudi Arabia study [22] showed that the patients with dual HCV and HBV infection had more decompensated liver disease. Most of these patients were classified in the Child-Pugh group C as compared to the controls $(36.8 \%$ vs $0 \%, \mathrm{p}<0.01)$. Markedly different anti-HCV positive rates $(\mathrm{P}<0.001)$ in hepatitis $\mathrm{B}$ patients in different clinical stages were discovered in a study from China [23]. The anti-HCV positive rate increased with severity of hepatitis in those patients. The suggestion that dual infection of $\mathrm{HBV}$ and $\mathrm{HCV}$ may enhance the severity of hepatitis was also supported by histological evidence. Zarski [24] compared the histological characteristics of patients with chronic hepatitis $B$ and $C$ with those of patients with chronic hepatitis $\mathrm{C}$ alone. Histological lesions were more severe in dual infection than in $\mathrm{HCV}$ single infection, including prevalence of cirrhosis, knodell score and piecemeal necrosis and fibrosis. In an Italian multicenter case-control study [25], the clinical impact of multiple virus infection was compared with a single $\mathrm{HBV}$ or $\mathrm{HCV}$ infection. Moderate or severe chronic hepatitis or cirrhosis were more frequent in patients with $\mathrm{HBV}$ and $\mathrm{HCV}$ coinfection $(62.9 \%$ of 65 patients) than in patients with HBV infection $(46.7 \%$ of $90, \mathrm{P}<0.05)$ or patient with $\mathrm{HCV}$ infection $(40.8 \%$ of $98, \mathrm{P}<0.005)$. These data showed that $\mathrm{HBV}$ and $\mathrm{HCV}$ dual infection increased the severity of histological lesions.

\section{HCV Superinfection in Individuals with Chronic HBV Infection}

Acute HCV superinfection in HBsAg carriers may be the major cause of fulminant/subfulminant hepatitis. Two independent studies from Taiwan [26, 27] have showed that a significant proportion of fulminant/subfulminant hepatitis in chronic HBsAg carriers could be attributed to HCV superinfection. Moreover, Chu et al [28] conducted a study to investigate the risk of fulminant hepatitis $C$ in relation to concurrent infection of HBV. Of 109 patients with acute hepatitis C, 11 patients $(10.1 \%)$ had the complication of FHF. The occurrence of fulminant hepatic failure (FHF) was closely related to concurrent $\mathrm{HBV}$ chronic infection. The incidence of FHF in patients with underlying chronic HBV infection was 23.1\% (9/39), which is significantly higher than in those without $(2.9 \%$ or 2/70). Recently, Liaw et al [17] studied the natural course following acute $\mathrm{HCV}$ superinfection in HBV infection. In this study, acute HCV superinfection in patients with chronic HBV infection is clinically severe during acute phase. Moreover, during a follow-up period of 1-21 years, patients with acute superinfection had a significantly higher cumulated incidence of cirrhosis $(48 \%$ at 10 years) and HCC (14\% at 10 years, $21 \%$ at 15 years, and $32 \%$ at 20 years) than acute HDV superinfection or active chronic hepatitis B. Generally, HCV superinfection can cause a much more severe liver disease in patients with chronic HBV infection.

\section{HBV Superinfection in Individuals with HCV Infection}

A few case reports suggest the association between HBV superinfection in HCV infection and severe clinical presentation $[29,30]$. A recent report investigated on the clinical presentation of $\mathrm{HBV}$ superinfection in $\mathrm{HCV}$ chronic carriers [31]. A severe clinical presentation (development of portosystemic encephalopathy or ascites or prothorombin activity lower than $25 \%$ ) was observed in $6(28.6 \%)$ patients in the patients with HBV superinfection in HCV chronic hepatitis and in none of those in the control group (patients with HBV infection alone). One of these 6 patients had fulminant hepatitis and died within a few days because no liver was available for transplantation. The study lends support to the notion that $\mathrm{HBV}$ superinfection may also aggravate the disease severity and increase the risk of fulminant hepatitis. All together, HBV and HCV dual infection, whether HBV on $\mathrm{HCV}$ or $\mathrm{HCV}$ on HBV, are characterized by a severe clinical and histological presentation.

\section{Occult HBV Infection in Patients with HCV Infection}

Occult HBV infection has frequently been identified in patients with HCV-related chronic hepatitis. Considerable data suggested that occult infection may contribute to chronic liver damage and the development of HCC [32, 33, 34, 35]. Cacciola [36] studied the prevalence and clinical significance of occult $\mathrm{HBV}$ infection in patients with chronic hepatitis $C$. The result showed that 21 of the 66 patients with HCV infection and occult HBV infection (33\%) had cirrhosis, as compared with 26 the 134 patients with HCV infection and no occult HBV infection $(19.8 \%, p=0.04)$. This suggests that occult $\mathrm{HBV}$ infection may interfere with the clinical outcome of chronic hepatitis $C$ and favor or accelerate the evolution to cirrhosis. Sagnelli [25] suggested that anti-HCV positive, anti-HBc-positive patients who lack both HBsAg and antiHBs might be a group of patients with a multiple HBV and HCV infection. HBV DNA by PCR was detected in $40.8 \%$ of 71 such patients in this study, which implies that nearly half of such patients could be classified as occult HBV infection. The clinical presentation in patients with anti-HCV-positive and anti-HBc-positive was as severe as in patients with dual HBV and HCV infection. This means that like dual HBV and HCV infection, occult HBV infection in chronic hepatitis $C$ could also aggravate the disease severity.

\section{Virus Interaction}

The interaction between $\mathrm{HBV}$ and $\mathrm{HCV}$ in coinfection patients has been investigated in clinical study and in vitro experiment. Suppression of HBV replication 
by HCV in acutely or chronically infected patients is welldescribed phenomenon. In vivo study in chimpanzees showed that acute HCV superinfection in chronic HBV infection resulted in marked reduction in the titer of serum HBsAg $[37,38]$. In clinical studies, the inhibition of HBV replication by HCV was also observed [25,39, 40]. Serum HBVDNA was found more frequently in patients with HBsAg+ / anti-HCV - than in patients with HBsAg+ /anti-HCV+ [25] and HBVDNA levels was lower in coinfections than in single infections [41]. Liaw et al [42] found that HCV infection might suppress HBV or even eliminate HBV and become sole cause of persistent hepatitis or ALT/AST elevation in a small number of patients. In a follow-up study of chronic HBV infection [42], the role of $\mathrm{HCV}$ in continuing hepatitis after termination of chronic HBsAg antigenemia was explored in a series of patients. Among 41 patients with persistent ALT elevation, 26 were seropositive for anti-HCV. Of those seropositive for anti-HCV, serum HBVDNA was not detectable, and serum HCVRNA was detected in 23 of the 26 hepatitis patients. Liver biopsy in 6 anti-HCV positive patients with continuing hepatitis showed features compatible with chronic hepatitis C. HCVRNA, but not HBVDNA, was detected in liver tissues of these 6 patients. The results provide direct evidence to confirm that HCV superinfection in patients with chronic HBV infection may not only terminate chronic HBsAg antigenemia but may ever usurp the role of $\mathrm{HBV}$ in chronic hepatitis to cause continuing ALT elevation.

The mechanisms accounting for the suppression of $\mathrm{HCV}$ on HBV were investigated by Shih et al [43]. Their findings suggest that HCV may directly interfere with $\mathrm{HBV}$ replication and furthermore identified the HCV core protein as a repressor of HBV production. They found a moderate 2-4 fold reduction of $\mathrm{HBV}$ mRNA and HBV antigen expression in the presence of HCV structure genes and a stronger up to 20 fold suppression of HBV particle secretion. Furthermore, the target structure of $\mathrm{HCV}$ core protein was identified in another study [44]. The results showed that full-length HCV core protein suppressed the HBV enhancer 1 up to 11-fold, the enhancer 2 3-4-fold. Suppression of $\mathrm{HBV}$ enhancer 1 by $\mathrm{HCV}$ core from genotype $1 \mathrm{~b}$ was stronger than by HCV core of genotypes $3 a$ or 1a. This trans-repression may contribute to suppression of HBV replication in patients coinfected with both viruses. However, until now it has been completely uncertain if or how HCV core may be released from the replication/translation complex of $\mathrm{HCV}$, which is a prerequisite for the many reported in vitro activities of isolated core expression systems.

The inhibition exerted by HBV on the HCV genome also has been shown in chronic $\mathrm{HBV} / \mathrm{HCV}$ concurrent infection. Zarski et al [24] compared virological characteristics of patients with chronic hepatitis B and C with those of patients suffering from chronic $C$ alone. The results suggest an inverse relationship between the replicative patterns of both viruses. The HCV RNA level was significantly decreased in HBV DNA positive patients compared with HBVDNA negative patients. An Italian multicenter case-control study [25] was performed on a high number of patients with chronic hepatitis from a multiple hepatitis virus infection who were compared with patients with chronic hepatitis caused by a single virus. In this study, HCVRNA was detected more frequently in patients with anti-HCV positive $190.7 \%$ of
130) than in patients with $\mathrm{HBsAg} /$ anti-HCV positive (65.2\% of $69, \mathrm{p}<0.001)$.

\section{Antivirus Therapy}

Few data exist on treatment of double infection. Some preliminary studies $[45,46]$ showed that patients with dual HBV and HCV infection had responded poorly to interferon (IFN) monotherapy. In an open trial of the efficacy of interferon-alpha $2 b$ (IFN-alpha) treatment on multiple infection, eight patients with chronic HBV and $\mathrm{HCV}$ were treated with recombinant IFN-alpha $2 \mathrm{~b}[3$ million units (MU), thrice weekly for 6 months]. Liver function tests normalized in two patients and one lost hepatitis B surface antigen (HBsAg) [45]. Silent HBV coinfection with $\mathrm{HCV}$ decreases the response to interferon. Sagnelli [47] reported that fewer patients with chronic hepatitis $\mathrm{C}$ and isolated anti-HBc have a sustained response to interferon-alpha treatment than those with chronic hepatitis C $(7.8 \%$ vs. $30.4 \%, p=0.009)$. Similar results have been observed by others in patients having silent HBV coinfection with HCV [48].

It has been suggested that a specific dose and duration of IFN regimen for the treatment of either HBV or HCV should be chosen based on which viral infection is determined to be active. In the attempt to verify whether the outcome of IFN therapy in patients with hepatitis B and hepatitis C coinfection can be improved, Villa [49] conducted a prospective, randomized trial with medium to high dosages of interferon three times a week for 6 months. Thirty patients with HBV-HCV coinfection, and chronic hepatitis were randomized to receive either 6 or 9 MU alpha-interferon three times a week for 6 months. Five patients treated with 9 MU IFN consistently cleared HCV RNA and HBV DNA, whereas none of those treated with 6 MU reacted in a similar fashion $(p=0.045)$. Responders showed significant improvement of histological activity index in comparison with nonresponders (mean Ishak score pre-treatment versus posttreatment $p=0.002)$. Long term follow-up showed that none of the patients treated with high doses developed cirrhosis whereas 4/14 treated with low doses did develop cirrhosis. The results indicate that with HBV$\mathrm{HCV}$ coinfection, a trial with high doses of interferon is strongly recommended. Recently, Chuang [50] conducted a case-control study to investigate the efficacy of interferon-alpha (IFN-alpha) and ribavirin combination therapy for patients with chronic hepatitis $C$ and $B$ virus (HCV/HBV) coinfection. Forty-two chronic HCV/HBVcoinfected patients (29 IFN-naive, 13 IFN-relapsed) and 84 $\mathrm{HCV}$-monoinfected controls, matched for age, sex and previous history of IFN-alpha therapy, were enrolled. All patients were treated with IFN-alpha-2b 6 MU three-times weekly plus ribavirin $1000-1200 \mathrm{mg}$ daily for 24 weeks. The rate of HCV sustained virological response (SVR) was comparable among IFN-naive and IFN-relapsed $\mathrm{HCV} / \mathrm{HBV}$-coinfected patients and IFN-naive and IFNrelapsed HCV-monoinfected patients $(69.0 \%, 69.2 \%, 67.2 \%$ and $57.7 \%$, respectively; intention-to-treat analysis). Of 16 baseline HBV viraemic patients, five (31.3\%) achieved HBV SVR, which correlated negatively to HCV genotype non- $1 \mathrm{~b}$ and HCV SVR. Only one $(6.3 \%)$ had simultaneous seroclearance of HCV and HBV. The author suggested that IFN-alpha/ribavirin combination therapy was effective for $\mathrm{HCV} / \mathrm{HBV}$-coinfected patients in eradicating $\mathrm{HCV}$ infection and might promote HBV seroclearance. 


\section{Dual Infection of $\mathrm{HBV}$ and $\mathrm{HCV}$ and hepatocellular carcinoma (HCC)}

HBV and HCV infections are confirmed causes of HCC. What's the combined effect of $\mathrm{HBV}$ and $\mathrm{HCV}$ coinfection on HCC? Accumulated epidemiological data suggested that coinfection with $\mathrm{HBV}$ and $\mathrm{HCV}$ could increase the risk for development of HCC. A case-control study [51] conducted in Qidong county (a higher incidence area of HCC in China) showed that the OR values for HCC were similar in patients with HBV (3.90) and HCV (3.89) infection, and highest in coinfection with HBV and HCV (6.48, see Table 2$)$. In a prospective study in Italy [52], 290 consecutive patients with cirrhosis were followed up. During a follow-up of 8-96 months, HCC was observed in $12.2 \%$ of anti-HCV-positive patients, in $19.6 \%$ of $\mathrm{HBsAg}$-positive patients, and in $40.0 \%$ of patients with dual HBsAg and anti-HCV positive. To clarify the roles of $\mathrm{HBV}$ and $\mathrm{HCV}$ on the risk for $\mathrm{HCC}$, a case-control study was conducted by Kirk in Gambia [53], a small country in West Africa where HCC is the most frequent cause of cancer death among men. In a multivariable logistic regression model, the HCC risk was similar (OR16.7), with only HBsAg or with only anti-HCV. HCC risk with dual HBsAg and anti-HCV (OR, 35.3) was nearly equal to that expected with an additive statistical interaction, but did not approach that expected with a multiplicative interaction.

Several studies have shown that patients with HCC who have antibody to $\mathrm{HCV}$ often possess $\mathrm{HBV}$ related serological markers [54,55,56]. Marusawa [57] have looked for the presence of seralogical markers of HBV in a large cohort of 2014 HBsAg negative Japanese patients with HCV infection. A large number of patients (49.9\%) with $\mathrm{HCV}$ related chronic liver disease including HCC were positive for anti-HBc. Patients with HCC were significantly more likely to have evidence of previous HBV infection than patients with either cirrhosis or chronic hepatitis. These data suggest that HBV infection, probably including latent infection, may play an important role in carcinogenesis in the patients with $\mathrm{HCV}$ infection.

Table 2. Coinfection with HBV and HCV and risk of HCC

\begin{tabular}{|c|c|c|c|c|c|}
\hline Variables & Case number & \multicolumn{2}{|c|}{ HCC case } & \multirow{2}{*}{ OR } & 95\%CL \\
\cline { 3 - 4 } & & No. & $\%$ & & \\
\hline HBV(-)HCV(-) & 118 & 13 & 11.2 & 1.00 & --- \\
\hline HBV $(+) H C V(-)$ & 184 & 79 & 42.9 & 3.90 & $2.49-6.11$ \\
\hline HBV $(-) H C V(+)$ & 7 & 3 & 42.8 & 3.89 & $1.31-11.53$ \\
\hline HBV $(+) H C V(+)$ & 21 & 15 & 71.4 & 6.48 & $3.53-11.89$ \\
\hline
\end{tabular}

\section{Research Direction}

New antiviral agents such as peginterferon, adefovir and entecavir have been licensed for treatment of patients with $\mathrm{HCV}$ or HBV. However, until now there is no standard of care available for treatment of patients with coinfection. Further clinical trails are needed to clarify the optimal treatment for such patients. Moreover, HCV genotype and HBV genotype were found to be associated with clinical outcome in single infection in many epidemiological studies. What is the role of genotype of $\mathrm{HBV}$ and $\mathrm{HCV}$ in the setting of coinfection? As for interaction between the two viruses, the mechanism of mutual inhibition is still unclear, especially for the suppression of HCV by HBV. Future research should focus on these issues.

\section{Conflict of interest}

The authors have declared that no conflict of interest exists.

\section{References}

1. Chen X, Xuan M, Wu D. Study of superinfection of HBV and HCV. Zhonghua Liu Xing Bing Xue Za Zhi. 1999 ;20:141-143.

2. Li W, Zhu Y, Hua Z. Exploration on the association between the pattern of $\mathrm{HBV}$ markers and infection of $\mathrm{HCV}$ among population. Zhonghua Liu Xing Bing Xue Za Zhi. 1994 ;15:212-214.

3. Sato S, Fujiyama S, Tanaka M, Yamasaki K, Kuramoto I, Kawano S, Sato T, et al. Coinfection of hepatitis $C$ virus in patients with chronic hepatitis B infection. J Hepatol. 1994 ;21:159-166

4. Ohkawa K, Hayashi N, Yuki N, Hagiwara H, Kato M, Yamamoto K, Eguchi $\mathrm{H}$, et al. Hepatitis $\mathrm{C}$ virus antibody and hepatitis $\mathrm{C}$ virus replication in chronic hepatitis B patients. J Hepatol 1994;21:509-514.

5. Liaw YF. Role of hepatitis $C$ virus in dual and triple hepatitis virus infection. Hepatology. 1995;22:1101-1108.

6. Chan CY, Lee SD, Wu JC, Hwang SJ, Wang YJ, Huang YS, Lo KJ. Superinfection with hepatitis $C$ virus in patients with symptomatic chronic hepatitis B. Scand J Infect Dis 1991;23:421-424.

7. Gaeta GB, Stornaiuolo G, Precone DF, Lobello S, Chiaramonte M, Stroffolini T, Colucci G, et al. Epidemiological and clinical burden of chronic hepatitis B virus/hepatitis C virus infection. A multicenter Italian study. J Hepatol 2003;39:1036-1041.

8. Di Marco V, Lo Iacono O, Camma C, Vaccaro A, Giunta M, Martorana G, Fuschi $P$, et al. The long-term course of chronic hepatitis B. Hepatology 1999;30:257-264.

9. Fattovich G, Tagger A, Brollo L, Giustina G, Pontisso P, Realdi G, Alberti A, et al. Hepatitis $C$ virus infection in chronic hepatitis B virus carriers. J Infect Dis 1991;163:400-402.

10. Crespo J, Lozano JL, de la Cruz F, Rodrigo L, Rodriguez M, San Miguel G, Artinano E, et al. Prevalence and significance of hepatitis C viremia in chronic active hepatitis B. Am J Gastroenterol 1994;89:1147-1151.

11. Pallas JR, Farinas-Alvarez C, Prieto D, Delgado-Rodriguez M. Coinfections by HIV, hepatitis B and hepatitis C in imprisoned injecting drug users. Eur J Epidemiol 1999;15:699-704.

12. Reddy GA, Dakshinamurthy KV, Neelaprasad P, Gangadhar T, Lakshmi V. Prevalence of HBV and HCV dual infection in patients on haemodialysis. Indian J Med Microbiol 2005;23:41-43.

13. Aroldi A, Lampertico P, Montagnino G, Passerini P, Villa M, Campise MR, Lunghi G, et al. Natural history of hepatitis B and C in renal allograft recipients. Transplantation 2005;79:1132-1136.

14. Kalinowska-Nowak A, Bociąga-Jasik M, Garlicki A, Skwara P. Prevalence of hepatotropic viruses HBV and HCV in HIV-infected patients from Southern region of Poland. Acta virologica 2000;44: 23-28.

15. Irshad M, Peter S. Spectrum of viral hepatitis in thalassemic children receiving multiple blood transfusions. Indian J Gastroenterol 2002;21:183-184.

16. Gaeta GB, Stornaiuolo G, Precone DF, Lobello S, Chiaramonte M, Stroffolini T, Colucci G, et al. Epidemiological and clinical burden of chronic hepatitis $B$ virus/hepatitis $C$ virus infection. A multicenter Italian study. J Hepatol 2003;39:1036-1041.

17. Liaw YF, Chen YC, Sheen IS, Chien RN, Yeh CT, Chu CM. Impact of acute hepatitis $C$ virus superinfection in patients with chronic hepatitis B virus infection. Gastroenterology 2004;126:1024-1029.

18. Mimms LT, Mosley JW, Hollinger FB, Aach RD, Stevens CE, Cunningham M, Vallari DV, et al. Effect of concurrent acute infection with hepatitis $C$ virus on acute hepatitis B virus infection. BMJ 1993;307(6912):1095-1097.

19. Sagnelli E, Coppola N, Messina V, Di Caprio D, Marrocco C, Marotta A, Onofrio M, et al. HBV superinfection in hepatitis $C$ virus chronic carriers, viral interaction, and clinical course. Hepatology 2002;36:1285-1291.

20. Chu CM, Liaw YF. Simultaneous acute hepatitis B virus and hepatitis $C$ virus infection leading to fulminant hepatitis and subsequent chronic hepatitis C. Clin Infect Dis 1995;20:703-705.

21. Alberti A,Pontisso P, Chemello L, Fattovitch G, Benvegnu L, Belussi F, De Mitri M. The interaction between hepatitis $B$ virus and 
hepatitis $C$ virus in acute and chronic liver disease. Journal of Hepatology 1995;22(suppl.1):38-41.

22. Mohamed A el al. Dual infection with hepatitis C and B viruses: clinical and histological study in Saudi patients. Hepatogastroenterology 1997;44:1404-1406.

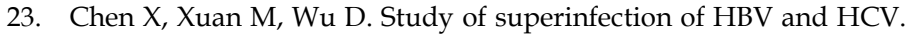
Zhonghua Liu Xing Bing Xue Za Zhi 1999 ;20:141-143.

24. Zarski JP, Bohn B, Bastie A, Pawlotsky JM, Baud M, Bost-Bezeaux F, Tran van Nhieu J, et al. Characteristics of patients with dual infection by hepatitis B and C viruses. J Hepatol 1998;28:27-33.

25. Sagnelli E, Coppola N, Scolastico C, Filippini P, Santantonio T, Stroffolini T, Piccinino F. Virologic and clinical expressions of reciprocal inhibitory effect of hepatitis B, C, and delta viruses in patients with chronic hepatitis. Hepatology 2000;32:1106-1110.

26. Wu JC, Chen CL, Hou MC, Chen TZ, Lee SD, Lo KJ. Multiple viral infection as the most common cause of fulminant and subfulminant viral hepatitis in an area endemic for hepatitis B: application and limitations of the polymerase chain reaction. Hepatology 1994 ;19:836-840.

27. $\mathrm{Chu} \mathrm{CM}$. The role of hepatitis $\mathrm{C}$ virus in fulminant viral hepatitis in an area with endemic hepatitis A and B. Gastroenterology 1994;107:189-195

28. Chu CM, Yeh CT, Liaw YF. Fulminant hepatic failure in acute hepatitis C: increased risk in chronic carriers of hepatitis B virus. Gut 1999;45:613-617

29. Wietzke P, Schott P, Braun F, Mihm S, Ramadori G. Clearance of HCV RNA in a chronic hepatitis $C$ virus-infected patient during acute hepatitis B virus superinfection. Liver 1999;19:348-353.

30. Liaw YF, Yeh CT, Tsai SL. Impact of acute hepatitis B virus superinfection on chronic hepatitis C virus infection. Am J Gastroenterology 2000;95:2978-2980.

31. Sagnelli E, Coppola N, Messina V, Di Caprio D, Marrocco C, Marotta A, Onofrio M, et al. HBV superinfection in hepatitis $C$ virus chronic carriers, viral interaction, and clinical course. Hepatology 2002;36:1285-1291.

32. Paterlini P, Driss F, Nalpas B, Pisi E, Franco D, Berthelot P, Brechot C. Persistence of hepatitis $B$ and hepatitis $C$ viral genomes in primary liver cancers from HBsAg-negative patients: a study of a low-endemic area. Hepatology 1993;17:20-29.

33. Koike K, Kobayashi M, Gondo M, Hayashi I, Osuga T, Takada S. Hepatitis B virus DNA is frequently found in liver biopsy samples from hepatitis $C$ virus-infected chronic hepatitis patients. J Med Virol 1998;54:249-255.

34. Huo TI, Wu JC, Lee PC, Chau GY, Lui WY, Tsay SH, Ting LT, et al. Sero-clearance of hepatitis B surface antigen in chronic carriers does not necessarily imply a good prognosis. Hepatology 1998;28:231236.

35. De Maria N, Colantoni A, Friedlander L, Leandro G, Idilman R, Harig J, Van Thiel DH. The impact of previous HBV infection on the course of chronic hepatitis C. Am J Gastroenterol 2000;95:3529-3536.

36. Cacciola I, Pollicino T, Squadrito G, Cerenzia G, Orlando ME, Raimondo G. Occult hepatitis B virus infection in patients with chronic hepatitis C liver disease. N Engl J Med 1999;341:22-26.

37. Brotman B, Prince AM, Huima T, Richardson L, van den Ende MC, Pfeifer U. Interference between non-A, non-B and hepatitis B virus infection in chimpanzees. J Med Virol 1983;11:191-205.

38. Bradley DW, Maynard JE, McCaustland KA, Murphy BL, Cook EH, Ebert JW. Non-A, non-B hepatitis in chimpanzees: interference with acute hepatitis A virus and chronic hepatitis B virus infections. J Med Virol 1983;11:207-213.

39. Pontisso P, Gerotto M, Benvegnu L, Chemello L, Alberti A. Coinfection by hepatitis B virus and hepatitis C virus. Antivir Ther 1998;3(Suppl 3):137-142.

40. Jardi R, Rodriguez F, Buti M, Costa X, Cotrina M, Galimany R, Esteban R, et al. Role of hepatitis B, C, and D viruses in dual and triple infection: influence of viral genotypes and hepatitis $\mathrm{B}$ precore and basal core promoter mutations on viral replicative interference. Hepatology 2001;34:404-410.

41. Crespo J, Lozano JL, Carte B, de las Heras B, de la Cruz F, PonsRomero F. Viral replication in patients with concomitant hepatitis B and C virus infections. Eur J Clin Microbiol Infect Dis 1997;16:445451.
42. Liaw YF, Tsai SL, Chang JJ, Sheen IS, Chien RN, Lin DY, Chu CM. Displacement of hepatitis B virus by hepatitis $C$ virus as the cause of continuing chronic hepatitis. Gastroenterology 1994;106:10481053.

43. Shih CM, Lo SJ, Miyamura T, Chen SY, Lee YH. Suppression of hepatitis $\mathrm{B}$ virus expression and replication by hepatitis $\mathrm{C}$ virus core protein in HuH-7 cells. J Virol 1993;67:5823-5832.

44. Schuttler CG, Fiedler N, Schmidt K, Repp R, Gerlich WH, Schaefer S. Suppression of hepatitis $B$ virus enhancer 1 and 2 by hepatitis $C$ virus core protein. J Hepatol 2002;37:855-862

45. Weltman MD, Brotodihardjo A, Crewe EB, Farrell GC, Bilous M, Grierson JM, Liddle C. Coinfection with hepatitis B and C or B, C and delta viruses results in severe chronic liver disease and responds poorly to interferon-alpha treatment. J Viral Hepat 1995;2:39-45.

46. Zignego AL, Fontana R, Puliti S, Barbagli S, Monti M, Careccia G, Giannelli F, et al. Relevance of inapparent coinfection by hepatitis B virus in alpha interferon-treated patients with hepatitis $C$ virus chronic hepatitis. J Med Virol 1997 ; 51:313-318.

47. Sagnelli E, Coppola N, Scolastico C, Mogavero AR, Stanzione M, Filippini P, Felaco FM, et al. Isolated anti-HBc in chronic hepatitis C predicts a poor response to interferon treatment. J Med Virol 2001;65:681-687.

48. Khattab E, Chemin I, Vuillermoz I, Vieux C, Mrani S, Guillaud O, Trepo C, et al. Analysis of HCV co-infection with occult hepatitis B virus in patients undergoing IFN therapy. J Clin Virol 2005;33:150157.

49. Villa E, Grottola A, Buttafoco P, Colantoni A, Bagni A, Ferretti I, Cremonini $\mathrm{C}$, et al. High doses of alpha-interferon are required in chronic hepatitis due to coinfection with hepatitis $\mathrm{B}$ virus and hepatitis $C$ virus: long term results of a prospective randomized trial. Am J Gastroenterol $2001 ; 96: 2973-2977$.

50. Chuang WL, Dai CY, Chang WY, Lee LP, Lin ZY, Chen SC, Hsieh MY, et al. Viral interaction and responses in chronic hepatitis $C$ and $\mathrm{B}$ coinfected patients with interferon-alpha plus ribavirin combination therapy. Antivir Ther 2005;10:125-133.

51. Ye B, Shen J, Xu Y. Etiologic study on the relationship between HBV, HCV and HCC. Zhonghua Liu Xing Bing Xue Za Zhi 1994 ;15:131-134.

52. Benvegnu L, Fattovich G, Noventa F, Tremolada F, Chemello L, Cecchetto A, Alberti A. Concurrent hepatitis B and C virus infection and risk of hepatocellular carcinoma in cirrhosis. A prospective study. Cancer 1994 ;74:2442-2448.

53. Kirk GD, Lesi OA, Mendy M, Akano AO, Sam O, Goedert JJ, Hainaut $P$, et al. The Gambia Liver Cancer Study: Infection with hepatitis B and C and the risk of hepatocellular carcinoma in West Africa. Hepatology 2004;39:211-219

54. Saito I, Miyamura T, Ohbayashi A, Harada H, Katayama T, Kikuchi S, Watanabe $Y$, et al. Hepatitis $C$ virus infection is associated with the development of hepatocellular carcinoma. Proc Natl Acad Sci USA 1990;87:6547-6549.

55. Chiba T, Matsuzaki Y, Abei M, Shoda J, Tanaka N, Osuga T, Aikawa T. The role of hepatitis B virus infection and heavy smoking in hepatitis C virus-related hepatocellular carcinoma. Am J Gastroenterol 1996;91:1195-1203

56. Ruiz J, Sangro B, Cuende JI, Beloqui O, Riezu-Boj JI, Herrero JI, Prieto J. Hepatitis B and C viral infections in patients with hepatocellular carcinoma. Hepatology 1992;16:637-641

57. Marusawa H, Osaki Y, Kimura T, Ito K, Yamashita Y, Eguchi T, Kudo M, et al. High prevalence of anti-hepatitis B virus serological markers in patients with hepatitis $C$ virus related chronic liver disease in Japan. Gut 1999 ;45:284-288.

\section{Author biography}

Jinlin Hou, MD, is Director and Professor of Hepatology Unit and Department of Infectious Diseases, Nanfang Hospital, Southern Medical University. Dr. Hou joined the University Department of Medicine of Nanfang Hospital since July 1984. Between 1993 and 1994, he received training in HBV molecular virology in St. Mary Hospital Medical School in London, UK. Between 2000 and 2001, he was as a visiting fellow at Institute of Hepatology, 
London. He has been invited to deliver talks in both national and international liver conferences for his expertise in viral hepatitis. His current researches include clinical management of viral hepatitis, and molecular virology and immunology of HBV infection.

Zhihua Liu, PhD, MD, work in Hepatology Unit and Department of Infectious Diseases, Nanfang Hospital, Southern Medical University. His research focuses on molecular virology of $\mathrm{HBV}$ and antiviral immunology with publications in international journals. 